\title{
Japanese physicists say SSC will hurt domestic research
}

Tokyo. An overwhelming majority of Japanese high-energy physicists oppose the US Superconducting Super Collider (SSC) because of fears that their country's potential $\$ 1.5$ billion contribution to the Texas laboratory will bankrupt domestic projects. Their opposition is likely to continue the erosion of US support for the proton-antiproton accelerator, still reeling from a vote last month by one house of the US Congress to kill the $\$ 8.25$-billion laboratory.

The startling lack of support became evident earlier this year during a rancorous meeting at the High-Energy Physics Laboratory (KEK) in Tsukuba science city. The debate at Tsukuba, which is recounted in detail in the June issue of the Japanese newsletter High Energy News, also reveals the absence of an effective mechanism for Japanese scientists to influence government science policy.

The Tsukuba meeting, held on 28 April, was called by the High Energy Committee, a small group of high-energy physicists trying to develop a consensus on future projects. It provided a rare occasion for an open discussion of priorities and, much to the surprise of committee members, a large number of high-energy physicists took advantage of the opportunity.

The meeting was supposed to focus on how university researchers could link up with plans by KEK to launch new domestic high-energy physics projects, including a B-factory (see below). But it quickly turned into a debate on the SSC.

One participant who opposes the SSC says that the attack was "a spontaneous revolution" after the chairman, Ycrikiyo Nagashima of Osaka University, tried to direct the discussion towards the issue of university participation in domestic projects. "In the past five years there has been no discussion of the SSC problem", complained one scientist, according to High Energy News.

Takahiko Kondo of KEK, the leading organizer of Japanese participation in the SSC, said that "we have made efforts to provide information in SSC symposia, extended High-Energy Committee meetings, and in High-Energy News". But his audience rebelled when he explained that US officials have "coupled" Japan's participation in supercollider science to its contribution to the construction costs of the SSC.

"That will bring our domestic plans into crisis", complained one participant. Replied Kondo, "it's not a crisis. It [the SSC] is a salvation. The SSC will act as a bulldozer to make a breach for future plans for the highenergy community". But one opponent, speaking anonymously after the meeting,

\section{B-factory tops Japanese wish list}

Tokyo. Japan's high-energy physicists may be divided in their opinion of the Superconducing Super Collider (SSC), but they are united behind what they want to build at home. Their priority is a B meson factory at the country's High-Energy Physics Laboratory (KEK), followed by a more ambitious proposal to build a Japan Linear Collider (JLC). But the fate of the JLC is very much dependent on the SSC.

The B-factory has emerged as the favoured next project because its cost - $¥ 40$ billion (US $\$ 320$ million) - can be fitted into the resources available to KEK. In addition, now that the US government has delayed consideration of proposals from the Stanford Linear Accelerator Center and Cornell University until at least 1997. Japan has a chance to be first.

Japan's B-factory would be built within the ring of KEK's present TRISTAN electron-positron collider. The idea is to build an electron-positron collider with a very high luminosity - about 100 times that of TRISTAN - to produce B mesons by the truckload. These mesons, which are composed of bottom quarks and antiquarks, will be used to test quark-mixing theories and the physics of the strong interaction force. The Ministry of Education, Science and Culture has already assigned a small research and development budget to KEK. Japan's high-energy physicists believe that the education ministry will eventually ask for money to build a B-factory, but not until the conclusion of talks between the United States and Japan on the SSC - certainly no sooner than the end of the year.

The future of the JLC is less certain. Researchers at KEK and Tokyo University want to build two linear colliders (linacs), each about ten kilometres long, that would collide electrons and positrons at very high energies. Initial plans called for two 500 $\mathrm{GeV}$ linacs to yield collisions at $1 \mathrm{TeV}$ (see Nature 344, 8; 1990). Recently, however, JLC's proponents have reduced the scope of the collider to $150 \mathrm{GeV}$ to save money and to simplify the technical challenges.

D.S.

\section{IMAGE UNAVAILABLE FOR COPYRIGHT REASONS}

\section{Yorikiyo Nagashima}

says that "if it's a bulldozer, it's a bulldozer with a hell of a lot of explosives that will kill Japanese science".

Out of about 800 high-energy physicists in Japan (including graduate students) only about 100 want to participate in the SSC, says Fumihiko Takasaki of KEK, who was asked by the Ministry of Education, Science and Culture to measure the level of support for the US project. And many of its supporters are expected to retire before the SSC is scheduled to be finished in 1999. In addition, says Takasaki, no high-energy physicists at Tokyo University or Kyoto University, Japan's two leading national universities, want to participate in the SSC, meaning that it will be hard to attract top graduate students to the project.

Nevertheless, the Japanese prime minister, Kiichi Miyazawa, agreed in January to a request by the US president, George Bush, to form a joint US-Japan working group on the project. Some Japanese scientists believe that the working group exists only because debate over the SSC has been "suppressed". One young researcher at the Tsukuba meeting called for the debate to be opened to the Japanese newspapers, but his idea was quickly squelched by senior scientists.

A member of the High Energy Committee says it was considered "politically expedient" not to publicize the divisions in the high-energy community. "If we stop the SSC, the money will not reappear", he says. Furthermore, there is concern that the highenergy physics community will suffer if their opposition helps to kill the SSC.

Proponents of the SSC have used this sentiment to silence dissent. But on this occasion the amount of money involved is so huge - the United States is asking Japan for about $¥ 200$ billion (US $\$ 1.5$ billion) that many Japanese high-energy physicists fear for the future of their own domestic projects.

David Swinbanks 